\title{
Non-Native English Teachers Interpretation of Rubrics Used for Assessing Students' Writing
}

\author{
Mei Lusiana Sitorus
}

Universitas Negeri Jakarta, Indonesia

\begin{abstract}
The benefits of rubrics as teaching learning tools have been identified specifically for performance-based assessment in language. In Indonesia, the ability to produce quality written work has become a necessity to complete higher education but it remained unclear how learning and assessment on this area were conducted. This paper focused on exploring the use of rubrics by four non-native teachers' working for a private ESL school in Indonesia for assessing students' writing tasks. The study investigated how the teachers' current practice and how they approached rubrics for assessing writing by means of both closed and open-ended surveys. Additionally, an analysis of the assessed essay against the rubrics was conducted to identify interrater reliability. The results showed that the teachers had positive attitude towards rubrics, used rubrics regularly and approached rubrics in a similar fashion which was to use them as an assessment tool but not learning tool. There was an identified interrater inconsistency in the scoring results. Additionally, the teachers put a lot more focus on Grammar, Spelling and Punctuation category than on the other two categories (Function \& Content, and Cohesion \& Coherence). The implication of the study calls for more effective use of rubrics as teaching and learning tools by the teachers as well as the provision of teacher training which enable the teachers to do so and consequently resulting in improvement of interrater reliability.
\end{abstract}

Keywords: rubrics, interpretation of rubrics, non-native teachers, English writing, writing assessment

\section{Introduction}

Using rubrics in assessing students work have become a common practice in the ESL field due to its many benefits confirmed by previous studies. Using rubrics generates many benefits for teachers as a tool in assessment and learning but also for students as a tool for reflection and a map of getting better at the intended learning areas (Brooks, 2013; Jonsson \& Svingby, 2007; Stevens \& Levi, 2006). The use of rubrics has been intended to tackle the complexity of scoring performance-based tests. In language studies, the focus of rubrics has been on the productive skills in language use namely speaking and writing (Broad, 2003; Miller, M.D., Linn, R.L., Gronlund, 2014).

However, writing assessment presented its own unique challenges in comparison to speaking assessment. One is on issue of plagiarism which has become more pertinent now with the advancement of technology. Hence, the use of plagiarism detector is writing assessment has been widely promoted especially in university level (Raz1, 2015). A more complex problem relies on the core challenges of academic writing components such as content, vocabulary, grammar as well as cognitive skills including thinking skills and social skills (Beck, 2009; Toba et al., 2019).

Additionally, Beck (2009) highlighted the gap of writing skills between high school and college students in the U.S acknowledging the need for better teaching of writing in high schools. Similarly, in Indonesia, the ability to write academic papers is crucial since the publication of academic paper for undergraduate, graduate and postgraduate students as a requirement for graduation has been mandated by the Directorate General of Higher Education (DIKTI), Ministry of National Education of Indonesia (Ratnawati et al., 2018; Rochmyaningsih, 2012). Moreover, in secondary education, the Indonesian national curriculum of English subject requires 
students to demonstrate writing skills. However, having a genre-based curriculum presented its own challenges in terms of developing writing skills as teachers focused heavily on reading skills.

The use of rubrics might be one solution to the improvement of students' writing ability. Rubrics specifically designed to assess writing can be beneficial for both teachers and students. Rubrics serves as both a reminder and tool for teachers to analyse beyond the level structures of students' written work (Brooks, 2013) which often become the whole focus of the assessment with disregard to other aspects of a good composition such as coherence and cohesiveness. Many have tried to classify the components to be assessed as to simplify the process of assessment without disregarding the main purposes of tasks assigned. A five-point rubric have been widely used in language assessment for writing. The first point, ideas, covers the content and message to be delivered through the writing piece; The form refers to how the writer organizes his ideas and presents his analysis; the flavour refers to the level of earnestness shown by the writer; mechanics refers to the use of punctuation, language rules, etc.; Finally, wording refers to the vocabulary choice made by the writer (Broad, 2003).

The benefits of rubrics for teachers include providing timely feedback, preparing students to use detailed feedback, encouraging critical thinking, facilitating communication with others, helping teachers to refine their teaching skills, and 'levelling the playing field'. In levelling the playing field, rubrics take the role of communicating clearly what are expected of the students which may be understood differently due to students' various background (Stevens \& Levi, 2006). The use of rubrics also increases consistent results in scoring performance-based assessments due to its comprehensive design while refining the quality of instructions and potentially improving learning activities (Jonsson \& Svingby, 2007). Additionally, it informs teachers especially novice teachers who will most likely use a pre-made assessment produced by the schools of the design and coverage of the assessment instruments.

The use of rubrics in learning by students have also shown positive results in students' progress. Students can utilize rubrics as a self-reflection tool to keep track of their progress with measurable units (Ismail et al., 2017; Sundeen, 2014). It also helps them to identify specific areas they need to work on (Razi, 2016) and reduces their anxiety towards taking the test (Arindra \& Ardi, 2020). However, these benefits can only be experienced by students if they are made aware to the students by the teachers. Hence, it is important for teacher to purposefully introduce and explain the use of rubrics and how to utilize them to the students so that the students can take full benefits of rubrics as a learning tool.

On the other hand, some issues regarding rubrics have been raised due too to its level of comprehensiveness and interrater reliability. The opposition of rubrics believes that rubrics that are too detailed do not accommodate teachers to value subjectivity in students' work and they don't help student becoming better at writing (Wilson, 2007) because the elaborated descriptions of each component being assessed may leave out areas that are a bit abstract such as originality and creativity. Some suggestion for this issue is to develop teacher's own rubrics On the other hand, rubrics that cover just general idea may result in inconsistency of results (Jonsson \& Svingby, 2007). A similar impact can also be the result of teachers' lack of ability and experience in using the rubrics which is referred to as interrater reliability (Jeong, 2015; Wang, 2010).

To compensate the weaknesses in using rubrics, it is believed that the debate whether rubrics bring more benefits or harm to be used as a tool in pedagogy should be based on these four questions: "What is the tool for?', 'In what context is it used?, 'Who decides?', and 'What ideological agenda drives those decisions?' (Hunt et al., 2013) which are inherent questions for the use of any pedagogical tools. Additionally, effective and regular trainings on the use of rubrics for teachers can reduce both interrater inconsistency and teacher's inaccuracy in interpreting the components of the rubrics (Lovorn \& Rezaei, 2011; Wang, 2010). Regardless of the debate, rubrics are still widely used as assessment tools for producing valid evaluation of complex competencies (Brooks, 2013). 
Despite the many benefits of using rubrics, a challenge in the use of rubrics particularly in assessing students' writing comes from the teachers as the raters, specifically for non-native teachers. Non-native teachers may have their language proficiency level as a constraint to the effectiveness of their teaching in comparison to their native counterparts. Tsang (2017) had conducted a study on this issue which resulted in the revelation that teacher's language proficiency affected their teaching however when a certain proficiency level was the effect was no longer significant in comparison to other pedagogical-related factors. Based on this finding, it could be concluded that once a certain level of language proficiency is attained, teaching including assessing process should not be affected as much. In spite of this preliminary findings, how Indonesian teachers as non-native teachers approach rubrics in writing assessment remains unclear. Moreover, in Indonesian classroom, rubrics use is not as popular as it is not provided nor required within the national curriculum. Leaving out the opportunities for rubrics to be used widely as assessment and learning tools.

Therefore, further studies on how teachers make use of the rubrics need to be done to find ways to improve the shortcoming. Rubrics descriptors are interpreted and used differently by each rater due to different raters' characteristics (Wang, 2010). Therefore, the individual qualities of the teachers influence to an extent the results of the scoring towards the students. With this assumption, the experience of non-native English teachers in utilizing the rubrics, specifically writing rubrics, will be different to an extent in comparison to their native counterparts. Focusing on the non-native English teacher, this paper aims to explore their use and interpretation of rubrics for writing assessment.

The writer investigated how four non-native teachers of English use the rubrics in evaluation students work. This paper aims to investigate how as non-native speakers, the teachers used rubrics in assessing students' written work to see how the teachers interpret the components provided in the rubrics. To address this issue, two research questions were proposed.

What are the specific procedures involved when the non-native teachers use rubrics in assessing writing?

To what extent do the feedbacks given by the teachers fit the descriptions written in the rubrics?

In order to answer these questions, the writer did a survey on four non-native teachers on how they would normally approach the use of rubrics for assessing students writing and then analysed the marked essay against the rubrics to see how accurately their descriptions fit the rubrics and what were the similarities and differences of the feedbacks given by these teachers. Then the results are presented in this paper along with the discussion points relevant to previous studies. Finally, conclusion and recommendations based on the results and discussion mark the end of the paper.

\section{Methodology}

\section{Research Design}

This study employed a convergent mixed methods design which make us of both quantitative and qualitative data by merging them to give better understanding of the problems studied (Creswell, 2012). This design fit this study to gain both overall and individual information on how the teachers approached the use of rubrics as well as to obtain numerical results of the scoring using the provided writing rubrics. To gather this data the three instruments were deployed. They were the writing test, writing rubrics, and questionnaires (close and open ended). The result of writing tests was analysed both quantitatively (resulting in scores) and qualitatively (resulting in written feedback) using the rubrics. Then the use of rubrics by the teachers was then investigated through open-ended questions. 


\section{Subjects}

The subjects of the study were four non-native English teachers at a private English language course in Bogor, Indonesia. The teachers were all female with teaching experience between 1-3 years. Their level of English proficiency was between upper intermediate (B2) to advance (C1) within the CEFR (Common European Framework of Reference for languages). They had received introductory training during their induction week at the beginning of the first year about the use of rubrics but had not yet received any in depth training on it ever since.

\section{Data collection}

The data collection took place in August 2019. A combination of closed and open-ended questionnaires were utilized as instruments in order to answer the first research question: what are the specific procedures involved when the non-native teachers use rubrics in assessing writing? The survey consisted of five closed questions taken from (Qasim \& Candidate, 2015) and the five guiding questions for the open-ended questionnaire were constructed by the writer to explore how teachers used rubrics prior to and after the writing tests to improve the validity of the closed question as stated by Lazarsfeld (as cited in Singer \& Couper, 2017). The open-ended survey was conducted to obtain qualitative data which aimed at gaining deeper insight on the practice of using rubrics (Johnson \& Christenen, 2014).

List of closed questions (Qasim \& Candidate, 2015):

1. Do you use a rubric to assess your students' writing?

2. Do you agree that rubrics provide the students with a clear idea of your assessment criteria?

3. Do you use one specific rubric to grade every writing assignment?

4. Do you feel that the students generally write better if the teacher provides them with a grading rubric ahead of time?

5. Does the students' performance reflect their understanding of your expectation from their work?

List of open-ended questions:

1. Normally, how early do you preview the rubrics for the written test?

2. Would you share the rubrics to the students prior to the test? Why/why not?

3. How do you approach the rubrics for scoring? Please describe it.

4. What is your overall opinion on the functionality of rubrics for assessing writing?

5. Would you prefer to use rubrics or not? Please provide reasons.

Additionally, the notes and scores given by the teachers on essays written by students with reference to the rubrics were collected to answer the second research question 'to what extent do the feedbacks given by the teachers fit the descriptions written in the rubrics?'. All four teachers had been asked to mark an essay written by one student of C1 level of CEFR (Global scale - Table 1 (CEFR 3.3): Common Reference levels) against the rubrics assigned by the language school they worked for. The essay required the students to write about 250 words of academic text.

The rubrics used consisted of three components: Function \& Content, Grammar, Spelling \& Punctuation, and Cohesion \& Coherence, with descriptors for scores of 1 to 5 per component with one represents the lowest quality and 5 represents the highest quality. The function and content refer to the length of the essay and the appropriateness of ideas to answer the questions. The grammar, spelling and punctuation is pretty much selfexplanatory. Finally, the cohesion and coherence refer to the organization of the paragraphs identified by effective use of conjunctions and progression in the development of ideas. For the purpose of this research, the 
teachers were not asked to do the marking in a particular way when using the rubrics to see how they would have done it in a regular situation.

\section{Data Analysis}

The results of the survey and interview were then decoded to find common themes in terms of assessment and teaching practice involving rubrics. Additionally, content analysis was conducted on the essays marked by the teachers to identify key words which represented the rubrics components. Content analysis is commonly used to analyse texts systematically with the end results of constructing categories based on the data obtained (Cohen et al., 2017). Referring to this, the researchers listed all the comments and highlighting written by the teachers and compare them to the rubrics descriptors to pinpoint the representation of each rubric component in the writing assessment done by the teachers. To triangulate the data, a separate set of open-ended questions were asked to confirm the result of the closed survey as well as to explore deeper the practice of utilizing rubrics.

Finally, a descriptive statistical analysis was conducted to see the frequency of the components of the rubrics shown in the assessment. The overall scores given by the teachers towards the same essays using the same rubrics of scoring were compared to see any conclusion can be drawn. The results were then used to generate discussions on similarities and differences.

\section{Results}

The data shows how the four non-native teachers confirmed using rubrics in assessing their students writing and that all of them agreed that rubrics provide the students with clear idea of their assessment criteria. Furthermore, all the teachers felt that students write better when given the grading rubrics ahead of time. Similarly, all the teachers agreed that the students' performance reflect their understanding of the teachers' expectations. However, the only split decision made by the teachers was on question no. 3 where half of the teachers used one specific rubric for every writing assignment while the other half did not.

\section{Questionnaires}

The closed questionnaire was divided into two categories. Questions 1 and 2 indicate activities prior to the test. Meanwhile, questions 3, 4 and 5 referred to post writing test activities with overall general impression of having used the rubrics.

Based on the results of the survey questions, all of the teachers check the rubrics for the writing test. However, only half of the teachers (T2 and T3) previewed the rubrics prior to the test session (Question 1) while the other half checked the rubrics on the same day of the test. For question no. 2, three out of four respondents stated they didn't share the full descriptors in the rubrics with their students, but all of them shared with the students the overall expectation of the rubrics based on the teachers' interpretations of the rubrics.

Furthermore, the result of the open-ended questionnaire showed that most teachers $(75 \%)$ previewed the rubrics prior to the day of the test but did not share them with the students. The same number of teachers admitted taking mental notes of the rubrics but did any other active actions towards it. In line with the initial survey, the teachers recognized the rubrics only as assessment tool and generally had positive attitude towards the use of rubrics for assessment tool. Overall, the responses for both closed and open-ended questionnaire were consistent. The teachers showed positive responses towards the use of rubrics in assessing writing but did not use it as a learning tool. 
Sample responses for open-ended questionnaire.

Q1: "Normally, how early do you preview the rubrics for the written test?"

T3: "I often preview the rubrics whenever the students have writing session in every unit, and I would mention one or two things they should do on their writing, especially when they have to do the test."

Q.2: "Would you share the rubrics to the students prior to the test? Why/ Why not?"

T2: "No but I would tell them what is expected from the writing assignment and see how ss build their writing from that."

Q.3 "How do you approach the rubrics for scoring? Please describe it."

T1: "I take it as parameters for grading the assignments, more or less like a check-list. If the student mostly fulfils the parameter, then they get the point."

Q.4: "What is your overall opinion on the functionality of rubrics for assessing writing?"

T1: "It helps a lot to remind us different aspects of writing skills that we need to take account when grading. It is quite specific as well."

Q.5: "Would you prefer to use rubrics or not? Please provide reasons."

T4: "I prefer to use rubric because it clearly provides me with the aspect that needs to be evaluated. Then, I can give students the score from the same reference."

The answers to question no. 3 revealed that all teachers used the rubrics against students writing by analysing key aspects expected by the rubrics. In addition to that, all of them also shared positive opinions on rubrics as a tool of assessing writing and would prefer to use them.

\section{Analyses of the Marked Essay}

The teachers involved in this study were provided with rubrics for writing assessment by the language school they are working in. For this study, they were asked to mark one academic essay instructed to be written with a minimum of 250 words. The rubrics consisted of three components (Function \& Content, Grammar, Spelling \& Punctuation, and Cohesion \& Coherence) yielding from 1 to 5 points per component.

Table 3.1 Errors Identified and Scoring

\section{Rubrics Components}

\section{(No. of Errors Identified)}

\begin{tabular}{lllllll}
\hline $\begin{array}{l}\text { Function, } \\
\text { Content }\end{array}$ & Scores/5 & $\begin{array}{l}\text { Grammar, } \\
\text { Spelling, } \\
\text { Punctuation }\end{array}$ & Scores/5 & $\begin{array}{l}\text { Cohesion, } \\
\text { Coherence }\end{array}$ & Scores/5 & $\begin{array}{l}\text { Overall } \\
\text { Scores }\end{array}$ \\
\hline 1 & 4 & 6 & 4 & 1 & 3 & 11 \\
\hline 0 & 4 & 12 & 4 & 0 & 4 & 12 \\
\hline 0 & 5 & 9 & 4 & 4 & 5 & 14 \\
\hline 3 & 4 & 16 & 4 & 2 & 5 & 13 \\
\hline
\end{tabular}


Based on the essay marked by the teachers, T1 highlighted and corrected 6 items related to the second category of Grammar, Spelling and Punctuation. In addition, she noted one sentence as ineffective and another as could be expressed 'differently'. The earlier one fell under Cohesion and Coherence while the latter one was under Functions \& Content. She awarded Function\& Content as well as Grammar, Spelling and Punctuation with 4 out of 5, while Cohesion and Coherence was at 3 .

As for T2, she marked and corrected 12 errors related to Grammar, Spelling and Punctuation, and none for category 2 and 3 . She gave all categories a 4 out of 5 .

T3 marked and corrected 9 items related to Grammar, Spelling and Punctuation and gave score of 4 . There were also four checklists to indicate the use of adverbs of sequence (first, second and third) and a cohesive device (even though); both fell under Cohesion and Coherence). She marked Function\& Content as well as Cohesion and Coherence with 5 out of 5. Finally, T4 marked 16 items related to Grammar, Spelling and Punctuation, three sentences (were crossed out) related to Functions \& Contents, and two items (both were cohesive devices) related to Cohesion and Coherence. The final scores were 4, 4 and 5 for each category respectively.

Overall, all respondents gave the same score of 4 out of 5 for Grammar, Spelling and Punctuation. Meanwhile, for Functions \& Contents $75 \%$ of the teacher gave 4 points, with $25 \%$ gave a higher point of 5 . Finally, for Cohesion and Coherence, fifty percent of the teachers gave full point of 5 out of 5 , and the rest gave points of 4 and 3 each. Furthermore, among all teacher, Functions \& Contents had the highest overall score followed by Cohesion and Coherence, and Grammar, Spelling and Punctuation, with one-point gap respectively.

\section{Discussions}

The results of the questionnaires were similar to an earlier study (Qasim \& Candidate, 2015) in which the results of his survey indicated that all respondents said yes to questions 1 and 2 from the closed questions while only half of the respondents use one specific rubrics for marking writing (Closed Question no.3). It was also the case for this survey. However, the writer suspected there was a possible ambiguity with the wording of question 3 (closed question) where the respondents might assume that they were asked if they used ONE specific rubrics for marking every writing assignment instead of using rubrics in general sense. Unfortunately, the writer missed the opportunity to confirm this with the respondents.

Another result of the open-ended question (no.1) indicated that three out of four teachers involved in this study only previewed the rubrics during the test day, with the other mentioned of previewing the rubrics during a writing practice prior to the test. This means that the teachers did not have a lot of time between making themselves familiar with the rubrics (which are provided by the language institution they work for) and the writing test. This indicates that the teachers did not take advantage of incorporating rubrics as a tool to support both teaching and learning as confirmed by previous studies (Andrade, 2000; Reynders et al., 2020). These findings could serve as reminders for the teachers and academic managers to take advantage of rubrics as a tool improving students' writing progressively.

Moreover, based on the teachers' answers for open-ended questions no 3, 4 and 5, it could be concluded that all teachers recognized the benefits of using rubrics in marking writing assignments in that rubrics provided specificity teachers needed to focus on. T1 mentioned "....different aspects of writing skills that we need to take account" and was supported by T4 saying "...I know the standard and element to be assessed. Then, I can assess students' writing fairly with the same assessment rubric". This was supported by another study in which teachers perceived rubrics as a means of improving consistency and fairness while marking students' written work (Atkinson \& Lim, 2013). For the final question in the open-ended survey, all teachers preferred to work with rubrics to assess writing as rubrics has "more details" and provides "clear reference". 
However, the final scores given by the four teachers were all different, with T3 giving the highest scores of 93\%, while $\mathrm{T} 1$ gave the lowest scores of $73 \%$. This was not a surprise. A similar difference in interrater reliability could be seen on a study of using rubrics to assess speaking where raters gave different rating to students' speaking performance (Caban, 2003). The reason for this difference could not be concluded in this study. It might be affected by teachers' level of English proficiency, experience or other background which require further study. It is also interesting to explore further how the numbers of errors identified could lead to the final scoring.

On the other hand, for Grammar, Spelling and Punctuation, all respondents gave the same score of four and all four identified the most errors in this category. The total errors identified for Grammar, Spelling and Punctuation was 43 items. Five items were identified under Cohesion and Coherence, and four items under Functions \& Contents. Some of the items identified under each category were redundant. These results were relevant with the argument that teachers tend to focus on sentence level structure (Brooks, 2013). Not a single correction was written in relations to Functions \& Contents which could mean that the teachers did not fully understand what were expected of the rubrics.

The help of rubrics was supposed to help reduce teachers' sole focus to grammatical structure, but in this case most of the teachers had only previewed the rubrics right before the writing test which might have affected their comprehension of the rubrics. Unfortunately, this research did not investigate further into this. But, it is clear further study should be done to pinpoint the problem and possibly lead to the solution finding as "the role of language-testing research as an activity of applied linguistics is to further our understanding of language learning and illuminate the still uncharted space of language use" (Davies, 2007).

This study was limited to a small number of respondents chosen based on convenience sampling with only one essay marked by the respondents. However, it has been recognized that the strength of a qualitative research such as this was to provide insight contextually (Dornyei Zoltan, 2007).

\section{Conclusion and Recommendation}

This paper aimed to describe the specific procedures used by the non-native teachers in using rubrics for assessing students' writing in this study as well as analysing to what extent the feedbacks given by the teachers fit into the rubrics descriptors. Overall, the responds approached the use of rubrics in a similar fashion in that they did not introduce the rubrics prior to the writing practice or test or incorporate the rubrics into learning activity. They mainly previewed the rubrics on the day of the test and used their own understanding of the rubrics and communicated the standards expected by the rubrics with the teachers' own words and examples. Additionally, they valued rubrics as an effective reference during the marking process and that they would opt for rubrics to assess writing given the chance.

As for the feedbacks given by the teachers, they were dominated by a huge gap of the identification and correction of Grammar, Spelling and Punctuation category. It was clear that the respondents focused more on this category despite the purpose of using rubrics was to raise awareness of other aspects of writing, which are thinking aspect criteria (Andrade, 2000) that are reflected on Function\& Content as well as Cohesion and Coherence categories.

It can be concluded that the respondents have not utilized the rubrics effectively for their own benefits as well as their students'. However, through the study, the teachers seemed to recognize that rubrics can be used as a learning tool. These findings hopefully will serve as reminders for the teachers and academic managers to optimize the use of rubrics as a tool in improving students' writing and to give equal weight to all writing components in the rubrics instead of focusing too much on Grammar, Spelling and Punctuation category (Jeong, 2015). 
Due to the limitation of the study designs, there was a lack of in-depth analysis on what considerations were involved in the way the teachers approach the use of rubrics in assessing students writing. In this case, an interview would serve as an effective source of detailed information as well as a means of improving the qualitative reliability of the results. Furthermore, involving more teachers and analysing more marked essays may result in a more conclusive findings.

\section{References}

Andrade, H. G. (2000). Using Rubrics to Promote Thinking and Learning. Educational Leadership, 58(3 SUPPL.), 22-26.

Arindra, M. Y., \& Ardi, P. (2020). The correlation between students' writing anxiety and the use of writing assessment rubrics. LEARN Journal: Language Education and Acquisition Research Network, 13(1).

Atkinson, D., \& Lim, S. L. (2013). Improving assessment processes in higher education: Student and teacher perceptions of the effectiveness of a rubric embedded in a LMS. Australasian Journal of Educational Technology, 29(5), 651-666. https://doi.org/10.14742/ajet.526

Beck, S. W. (2009). Composition across secondary and post-secondary contexts: Cognitive, textual and social dimensions. Cambridge Journal of Education, 39(3). https://doi.org/10.1080/03057640903103710

Broad, B. (2003). What we really value: Beyond Rubrics in teaching and assessing writing. In What We Really Value: Beyond Rubrics in Teaching and Assessing Writing.

Brooks, G. (2013). Assessment and Academic Writing: A Look at the Use of Rubrics in the Second Language Writing Classroom. Kwansei Gakuin University Humanities Review, 17(17), 227-240. http://kgur.kwansei.ac.jp/dspace/handle/10236/10548

Caban, H. L. (2003). Rater Group Bias in the Speaking Assessment of Four L1 Japanese ESL Students. Second Language Studies, 21(2), 1-44. http://www.hawaii.edu/sls/sls/wp-content/uploads/2011/06/Caban.pdf

Cohen, L., Lawrence, M., \& Morrison, K. (2017). Research methods in education. Routledge.

Creswell, J. W. (2012). Educational research: Planning, conducting, and evaluating quantitative and qualitative research. In Educational Research (Vol. 4). https://doi.org/10.1017/CBO9781107415324.004

Davies, A. (2007). An introduction to applied linguistics. Edinburgh University Press Ltd. https://doi.org/10.1093/elt/cci013

Dornyei Zoltan. (2007). Research methods in applied linguistics: Quantitative, qualitative, and mixed methodologies. Oxford university Press.

Hunt, T., Carper, J., Lasley, T., Raisch, C., \& Bowman, C. L. (2013). National Council of Teachers of English. Encyclopedia of Educational Reform and Dissent, 97(4), 87-92. https://doi.org/10.4135/9781412957403.n296

Ismail, I., Jabri, U., Rahmat, \& Musdalifah. (2017). Rubrics-Based Assessment as a Teaching Strategy of Writing Journal for Novice Authors. International Conference on Education, 1(1).

Jeong, H. (2015). Rubrics in the classroom: do teachers really follow them? Language Testing in Asia, 5(1). https://doi.org/10.1186/s40468-015-0013-5

Johnson, R. B., \& Christenen, L. (2014). Educational Research :Quantitative, Qualitative, and Mixed Methods Approaches. In SAGE Publications, Inc.

Jonsson, A., \& Svingby, G. (2007). The use of scoring rubrics: Reliability, validity and educational consequences. In Educational Research Review (Vol. 2, Issue 2). https://doi.org/10.1016/j.edurev.2007.05.002

Lovorn, M. G., \& Rezaei, A. R. (2011). Assessing the assessment: Rubrics training for pre-service and new inservice teachers. Practical Assessment, Research and Evaluation, 16(16).

Miller, M.D., Linn, R.L., Gronlund, N. . (2014). Measurement and assessment in teaching. Igarss 2014, 1.

Qasim, A., \& Candidate, P. (2015). Using Rubrics to Assess Writing: Pros and Cons in Pakistani Teachers'

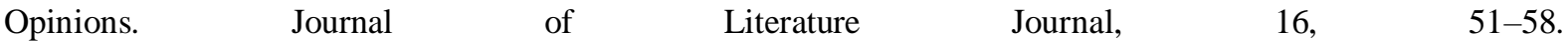
http://www.iiste.org/Journals/index.php/JLLL/article/viewFile/27152/27835 
Ratnawati, R., Faridah, D., Anam, S., \& Retnaningdyah, P. (2018). Exploring Academic Writing Needs of Indonesian EFL Undergraduate Students. Arab World English Journal, 9(4), 420-432. https://doi.org/10.24093/awej/vol9no4.31

Razi, A. (2016). Homeschooling: an Alternative Education in Indonesia. International Journal of Nusantara Islam, 4(2), 75-84. https://doi.org/10.15575/ijni.v4i2.973

Raz1, S. (2015). Development of a Rubric to Assess Academic Writing Incorporating Plagiarism Detectors. SAGE Open, 5(2). https://doi.org/10.1177/2158244015590162

Reynders, G., Lantz, J., Ruder, S. M., Stanford, C. L., \& Cole, R. S. (2020). Rubrics to assess critical thinking and information processing in undergraduate STEM courses. International Journal of STEM Education, 7(1). https://doi.org/10.1186/s40594-020-00208-5

Rochmyaningsih, D. (2012). Indonesia Makes Research Publication A Graduation Requirement For All Students - Asian Scientist Magazine. https://www.asianscientist.com/2012/03/academia/indonesia-dikti-aptisipublication-a-graduation-requirement-for-all-students-2012/

Singer, E. ; \& Couper, M. P. (2017). Some Methodological Uses of Responses to Open Questions and other Verbatim Comments in Quantitative Surveys. Methods, Data, Analyses, 11(2).

Stevens, D. D., \& Levi, A. (2006). Essays on Teaching Excellence Leveling the Field: Using Rubrics to Achieve Greater Equity in Teaching and Grading. Development, 17(1), 2005-2006.

Sundeen, T. H. (2014). Instructional rubrics: Effects of presentation options on writing quality. Assessing Writing, 21. https://doi.org/10.1016/j.asw.2014.03.003

Toba, R., Noor, W. N., \& Sanu, L. O. (2019). The Current Issues of Indonesian EFL Students' Writing Skills: Ability, Problem, and Reason in Writing Comparison and Contrast Essay. Dinamika Ilmu, 19(1), 57-73. https://doi.org/10.21093/di.v19i1.1506

Tsang, A. (2017). EFL/ESL Teachers' General Language Proficiency and Learners' Engagement. RELC Journal, 48(1). https://doi.org/10.1177/0033688217690060

Wang, B. (2010). On Rater Agreement and Rater Training. English Language Teaching, 3(1). https://doi.org/10.5539/elt.v3n1p108

Wilson, M. (2007). Why I Won't Be Using Rubrics to Respond to Students' Writing. English Journal, 96, 62. https://doi.org/10.2307/30047167 